\title{
Novedades sobre la tipología de las ánforas Dressel 2-4 tarraconenses
}

\section{New Data on Dressel 2-4 Tarraconensis Typology}

\author{
Piero Berni Millet \\ Institut Català d'Arqueologia Clàssica (Tarragona)
}

\section{RESUMEN}

El nombre canónico Dressel 2-4 se utiliza tradicionalmente en el argot científico para señalar a las ánforas vinícolas más representativas de época romana altoimperial, especialmente aquellas producidas en la vertiente occidental del Mediterráneo. Se trata de una definición genérica y al mismo tiempo ambigua que agrupa tres formas sucesivas de la tabla tipológica de Dressel en CIL XV, con una función económica común a través de un diseño afín, pero con valores diferentes, como vamos a ver, llenos de contradicciones. Desde que André Tchernia diera a conocer en 1971 a la comunidad internacional la existencia de hornos en Cataluña para producir esta clase de ánfora, el concepto de "Dressel 2-4 tarraconense" se ha convertido en una constante que encontramos, en la práctica, ejemplificada en la casi totalidad de los trabajos publicados hasta nuestros días. Para comprender su razón de ser, la naturaleza del nombre, y sus límites científicos como clasificación tipológica, hemos creído necesario llevar a cabo un nuevo análisis general de los datos publicados hasta ahora. Esta labor ha dado como resultado la confección del primer modelo descriptivo con el que poder datar las ánforas layetanas con precisión. Asimismo, la sistematización en el tiempo de sus variantes evolutivas ha hecho posible percibir un cambio en la dinámica comercial de los vinos por la coyuntura "calidad versus cantidad".

\section{SUMMARY}

The canonical name Dressel 2-4 had been used traditionally in scientific studies to nominate the most representative roman wine amphora from the High Roman Empire, especially those produced in the western Mediterranean basin. This is a generic and ambiguous definition including three Dressel CIL XV's successive types. As we will see, this three types have different meaning, although a common economic function and a related design. Since 1971, when André Tchernia brought to the international community the existence of kilns in Catalonia to produce this kind of amphora, the concept of "Dressel 2-4 tarraconensis" become the standard denomination in almost all the studies published to date. To understand its raison d'être, the nature of the name, and its scientific limits as a typological classification, we start from a new, and yet necessary, general analysis of all the published data existing on the subject. The result of this work has been the construction of the first descriptive model to precisely date the Laietana amphorae. Finally, the systematization of evolutionary sub-types over time has revealed a change in the commercial dynamics of wines by the conjuncture "quality versus quantity".

PALABRAS CLAVES: Hispania Citerior Tarraconensis; Layetania; vino; producción y comercio; tipología ánforas romanas; Dressel 2-4.

KEY WORDS: Hispania Citerior Tarraconensis; Laietana; Wine; Production and Trade; Roman Amphora Typology; Dressel 2-4.

\section{CASTRO PRETORIO: ORIGEN DE LAS FOR- MAS 2, 3 Y 4 DE DRESSEL}

El epigrafista y arqueólogo ítalo-alemán Heinrich Dressel (1845-1920), padre de la anforología romana y del instrumentum domesticum inscriptum, no tuvo intención de hacer una clasificación tipológica de las ánforas romanas cuando se le encomendó la ardua tarea de catalogar y descifrar para el CIL XV las inscripciones escritas sobre esta clase de material cerámico en Roma. Al estudiar de urgencia en 1878 el extraordinario hallazgo de Castro Pretorio, una potente fosa rellenada con ánforas de procedencias diversas, muchas de las cuales todavía enteras y con tituli picti en buen estado de conservación, se percató de la relación existente entre las inscripciones y la forma del contenedor. Dressel comprendió que la relación envase-contenido podría resultar de interés a la investigación para ayudar a determinar el uso de los recipientes anfóricos, lo que le motivó a publicar su primera tabla tipológica con las 19 formas constatadas en este yacimiento (Dressel 1879: 39-40, Tav. VIIVIII). Posteriormente, incluiría en el CIL XV la tabla definitiva con los mismos dibujos de Castro Pretorio pero con otro orden y numeración, sumando nuevas 
piezas, hasta un total de 45 formas, la cifra definitiva de ánforas con inscripciones documentadas por él en Roma. Las formas 13, 14 y 17 de Castro Pretorio, objetos del presente estudio, se corresponden a los números 2, 3 y 4 de la tabla tipológica de CIL XV (Figura 1). La edad, el origen y la función de estos tres recipientes afines pudieron ser, hasta cierto punto, resueltos por Dressel con la lectura y el estudio de las inscripciones que portaban.

El depósito de Castro Pretorio se formó en un sólo momento con diferentes clases de ánforas de vino, aceite y garum. Dressel (1879: 194-195) fecha ese momento no más tarde de la mitad del primer siglo de la era actual, siendo la datación consular más moderna del año 45 d.C. ${ }^{1}$ Cabe pensar pues, que la mayor parte de las ánforas utilizadas para rellenar la fosa hubiesen sido consumidas de reciente durante el período julio-claudio del segundo cuarto del s. I d.C. ${ }^{2}$ También se reaprovecharon algunas ánforas de edad más antigua ${ }^{3}$, principalmente las de contenido vinario, que suelen estar provistas de fecha consular para indicar el año de nacimiento del vino envasado ${ }^{4}$.

\footnotetext{
${ }^{1}$ Siguiendo a Zevi (1966: 211), la datación podría subirse a un momento preflavio por el sello GANTQVIETI en Dressel 20 (CIL XV 2703d), que Tchernia (1964: 419) data en la segunda mitad del siglo I d.C. por hallarse también en Pompeya. Nosotros lo tenemos documentado en el campamento militar de Kops Plateau en Nimega (Holanda), cuyo abandono se fecha con la revuelta bátava del año 69 d.C. (Almeida et alii 2014).

${ }^{2}$ Dato confirmado por la importante presencia de ánforas globulares Dressel 20 julio-claudias en dicho depósito, con inscripciones a tinta marcadamente arcaicas y de tamaño inferior a las conocidas en el Testaccio. Así como por los habituales sellos béticos que portaban estas ánforas del período Claudio-Nerón (PSAVITI, LVALSA, LCAE, SCLC, MAELIALEX, LVIVCV, MAR, etc.). Por otra parte, entre las ánforas vinarias adriáticas del tipo Dressel 6A existe una alta representación del sello T.H.B (21 ejemplares en CIL XV 2905), datado en Magdalensberg con Calígula por un titulus pictus del año 38 d.C. con la mención explícita a un (vinum) Kalab(rum) producido cuatro años antes (Piccottini 1997).

${ }^{3}$ Las ánforas olearias son un buen indicador en este sentido debido a la corta vida del aceite, cuyo consumo suele establecerse para un año o año y medio después del envasado. Dressel recoge tres ánforas "Dressel 26 similis" (CIL XV $3657,3658 \mathrm{a}-\mathrm{b})$ que manejan el mismo esquema epigráfico de la Dressel 20. Se trata del último prototipo oleario de cuerpo ovalado predecesor del ánfora globular. Se conoce generalmente con el nombre de Haltern 71 por los contextos militares de Germania (González Cesteros 2014: 376-380). Se data con un horizonte tardoaugusteo y tiberiano (Berni 1998: 31; García Vargas, Almeida y González Cesteros 2011: 238-242).

${ }^{4}$ Entre la datación más moderna del año 45 d.C. y la más antigua corría un período de 79 años. Ánforas de edad más reciente se encontraron en un estrato inferior a aquel donde estaban las ánforas con las fechas más antiguas. Entre la mayoría de los envases vinarios de aquel período julio-claudio se colocaron ánforas Dressel 1, algunas pocas septuagenarias y otras de Gran Reserva que los romanos pudientes solían guardar por largo tiempo en sus bodegas. Dressel justifica este hecho, aparentemente insólito, con las odas de Horacio, quien
}

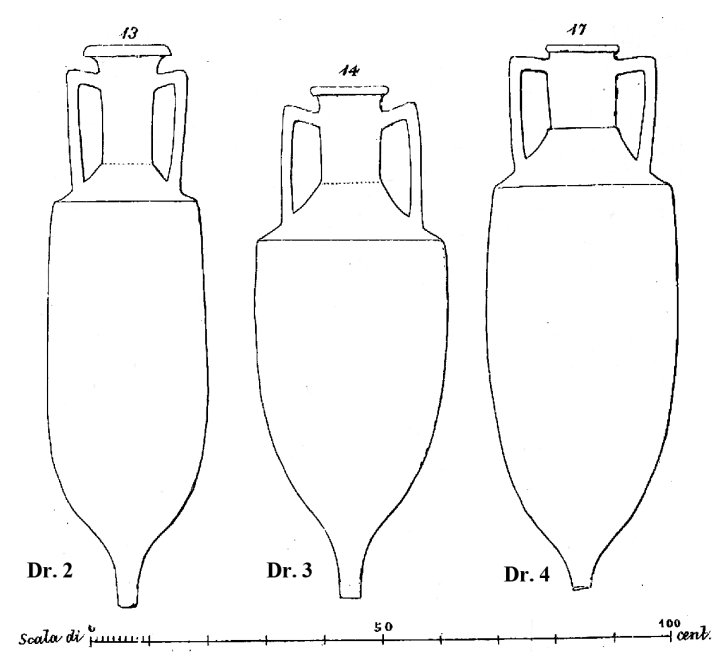

Figura 1. Formas 13, 14 y 17 de Castro Pretorio (2, 3 y 4 en CIL XV).

Las tres formas vinarias que han dado nombre a la Dressel 2-4 suman en total medio centenar de ejemplares en las publicaciones de Castro Pretorio y CIL XV. La forma 13 (Dressel 2) es la mejor representada con el $48 \%$ de los datos catalogados, seguida a moderada distancia por la forma 14 (Dressel 3) con el $32 \%$, y bastante más lejos la forma 17 (Dressel 4) con el $18 \%$. La escala de estos valores se explica, como veremos, por la distinta edad de los recipientes vinarios y el momento de reaprovechamiento de todas estas ánforas. La forma 13 (Dressel 2), más alta y de cuerpo estrecho, corresponde al modelo característico de la fase julio-claudia. Las formas 14 y 17 (Dressel 3 y 4), de menor altura y cuerpo abombado, son dos modelos ancestrales del período anterior tardoaugusteo y tiberiano. Esta secuencia crono-tipológica debe ser entendida en sentido amplio, pues del examen de las inscripciones consulares vemos que no es fácil establecer una regla absoluta de comportamiento para todos los casos, al existir solapamientos de fechas entre los tres tipos de ánforas ${ }^{5}$. El motivo de esta encrucijada

bebía vino de treinta y más años (Od. III, 21 v.1) y tenía en sus bodegas reservas de $c a$. 70 años ( $O d$. III, 14 v. 18). Véase a propósito Tchernia 1986: 201 ss., quien nos habla de los grandes caldos que se consumen envejecidos muchos años después de haberse producido.

5 Tres ejemplares de la forma 13 (Dressel 2) dieron dataciones consulares para un horizonte grosso modo tiberiano: año 13 d.C. (CIL XV 4565), año 29 d.C. (CIL XV 4603), años 29 y 36 d.C. (CIL XV 4573). La forma 14 (Dressel 3) sólo cuenta en Castro Pretorio con una datación consular del año 32 d.C. (CIL XV 4576), seis años por encima del 26 d.C. escrita en otra ánfora Dressel 3 estudiada por Dressel en el depósito de las termas de Diocleciano (CIL XV 4531). La forma 17 (Dressel 4) tiene una datación tardoaugustea del año 8 a.C. (CIL XV 4609) y otra tiberiana del año 24 d.C. (CIL 


\begin{tabular}{|c|c|c|c|}
\hline CIL XV & Forma & Epigrafía & Origen \\
\hline $4623+3513$ & Dressel 3 & $\begin{array}{l}\text { titulus + sellos RA y CLAS/ } \\
\text { PPARI }\end{array}$ & $\begin{array}{l}\text { Can Tintorer (Baix Llobregat) (Berni } \\
\text { y Carreras 2013: } \mathrm{n}^{\circ} \text { 104) }\end{array}$ \\
\hline 4577 & Dressel 3 similis & Lauronense & Layetania oriental \\
\hline $4578+3503$ & Dressel 2 & Lauronense + sello PHAE & $\begin{array}{l}\text { Layetania oriental (Berni y Carreras } \\
\text { 2013: } \mathrm{n}^{\circ} 142 \text { ) }\end{array}$ \\
\hline $4627+3506 b$ & Dressel 2 & $\begin{array}{l}\text { titulus + sello PLOC + } \\
\text { grafito } \mathrm{Ca}(\text { ) }\end{array}$ & $\begin{array}{l}\text { Sant Vicenç dels Horts (Baix } \\
\text { Llobregat) (Berni y Carreras 2013: } \\
\mathrm{n}^{\circ} \text { 94) }\end{array}$ \\
\hline $4651+3437$ & Dressel 2 & $\begin{array}{l}\text { titulus + sello CRE + grafito } \\
\text { M }\end{array}$ & $\begin{array}{l}\text { véase CRES en Can Pedrerol (Baix } \\
\text { Llobregat) (Berni y Carreras 2013: } \\
n^{\circ} 41 \text { ) }\end{array}$ \\
\hline 4579 & Dressel 2 similis & Lauronense & Layetania oriental \\
\hline $4626+3491+3616 \mathrm{rr}$ & \begin{tabular}{|l} 
Dressel 2 o \\
Dressel 4 similis
\end{tabular} & titulus + sello NP + grafito & $\begin{array}{l}\text { Iluro (Mataró) (Pascual 1977: } 63 \mathrm{n}^{\circ} \\
\text { 95) }\end{array}$ \\
\hline
\end{tabular}

Figura 2. Ánforas layetanas en Castro Pretorio.

parece deberse al hecho de que, tras estas tres formas, se esconden vinos de diverso origen geográfico con distintos indicadores económicos, envasados en ánforas afines pero con rasgos morfológicos propios de cada área productora ${ }^{6}$. Estos vinos son en gran número de Italia (Campania, Lacio, Etruria), los hay también de las provincias Narbonense y Tarraconense, sólo un ejemplar Dressel 3 similis con escritura griega es supuestamente oriental (CIL XV 4618). Los vinos galos e hispanos tienen, respectivamente, las denominaciones de origen de Béziers y Lauro. Se encuentran registrados indistintamente sobre las formas 13 (Dressel 2) y 14 (Dressel 3), no hay rastro de estos caldos en la forma 17 (Dressel 4).

En la actualidad, nos encontramos en condiciones inmejorables para llevar a cabo un análisis más riguroso de las inscripciones de Castro Pretorio, contrastando los datos epigráficos de Dressel (sellos, grafitos y tituli picti) con la abundante información publicada hasta nuestros días. Podemos confirmar que el depósito contó con un nutrido conjunto de ánforas

XV 4568). Por otro lado, una campana superior de la forma 13 o 14 (Dressel 2 o 3) lleva dos dataciones consulares de época tardoaugustea, la primera del año 2 a.C. indica el nacimiento del vino, la segunda del año 3 d.C. su envasado en el ánfora (CIL XV 4571). Bien lejos queda la fecha 28 o 27 a.C. sobre Dressel 3 similis con escritura griega (CIL XV 4618).

${ }^{6}$ Vinos de Campania con las formas 13 y 14: Campanum (CIL XV 4532 = Dr. 2), Beneventanum (CIL XV 4544= Dr. 3), Surrentinum (CIL XV $4592=$ Dr. 3 similis). Vinos del Lacio con la forma 17: Fundanum (CIL XV $4568=$ Dr. 4). Vinos de Etruria con la forma 13: Veientanum (CIL XV 4595 $=$ Dr. 2 similis). Vinos de Galia Narbonense con las formas 13 y 14: Baeterrense (CIL XV 4543 = Dr. 2; CIL XV 4542 $=$ Dr. 3 similis). Vinos de Tarraconense con las formas $13 \mathrm{y}$ 14: Lauronense (CIL XV 4578 = Dr. 2; CIL XV $4579=$ Dr. 2 similis; CIL XV $4577=$ Dr. 3 similis $)$. tarraconenses, mayoritariamente de origen layetano, asimilable a las formas 13 (Dressel 2) y 14 (Dressel 3). Hasta siete ánforas de Castro Pretorio se identifican como layetanas por la información de CIL XV, cinco de la presunta forma 13 julio-claudia (Dressel 2), dos para la forma 14 (Dressel 3) aparentemente menos evolucionada. En ambos grupos hay constancia de contenedores fabricados a los largo de las dos vertientes geográficas de la Layetania (Figura 6), la occidental que daba salida al copioso vino "layetano" (comarcas del Barcelonés, Baix Llobregat y Vallés Occidental), y la oriental del afamado vino Lauronense (El Maresme y Vallés Oriental) ${ }^{7}$. Los datos epigráficos se resumen en la tabla de la Figura 2.

Sobre la base de los siete testimonios que figuran en la tabla llegamos a las siguientes conclusiones. Las ánforas layetanas se identifican manifiestamente con las Dressel 2 y Dressel 3, quedando excluida la Dressel 4 por falta de testimonios seguros ${ }^{8}$, a pesar

\footnotetext{
${ }^{7}$ En CIL XV existen más sellos con un origen layetano. De la vertiente occidental (Baix Llobregat) son los siguientes: PLOCAM + grafito AL (3506a) sobre pivote de Dressel 2; SEC + EVD (3523), SOS + QVA (3530) y QVA + DE (3540) en pivotes macizos sueltos (in pede acuminato); quizá también ASCL (3405) sobre pivote de Dressel 3 similis. De la vertiente oriental (Maresme, Vallés Oriental) son los siguientes: NP (3491) inciso en campana de Dressel 4; ·COR - (2789) sobre pivote suelto; quizá lo sea también el sello CHR (3428) con las tres letras formado un nexo, en cartela rectangular, sobre pivote de Dressel 4.

${ }^{8}$ La información epigráfica sobre la forma Dressel 4 se ciñe a un grupo de ánforas de origen itálico. En CIL XV contamos con dos fechas consulares polarizadas entre los años 8 a.C. (CIL XV 4609) y 24 d.C. (CIL XV 4568), un arco de tiempo amplio que tiene parangón con los años de vida de la Dressel 3. Varios ejemplares de Castro Pretorio presentan sellos en el cuello con los nombres CLEMES (CIL XV 3433), AGATHOPV·F (CIL XV 3396, Dressel 4 similis),
} 
del titubeo de Dressel en la clasificación del ejemplar con sello NP $(4626+3491+3616 \mathrm{rr})^{9}$. Al cotejar los rasgos de las ánforas selladas (PHAE, PLOC, NP) con otros paralelos foráneos se observa una clara correspondencia morfológica, sin que existan mezclas de las dos formas con la misma marca. Al cotejar los sellos con las dataciones que proporcionan algunos pecios (Figura 4) se confirma el horizonte julio-claudio de la forma Dressel 2, así como el ciclo de vida anterior de la Dressel 3. La mayor presencia de testimonios de Dressel 2 sobre Dressel 3 se justifica, como ya habíamos avanzado, por el momento de cierre del depósito anfórico de Castro Pretorio, debido al uso mayoritario de contenedores de edad julio-claudia. Este detalle también ha sido corroborado por André Tchernia, quien vio personalmente el material anfórico de Castro Pretorio, y al hablar del sello PHAE nos dice que su forma (Dressel 2) era de lo más común en dicho depósito, con otros siete ejemplares idénticos de cuerpo fusiforme y punta alargada (Tchernia 1971: 73). También resulta de interés los matices de Dressel cuando se vale del atributo similis (CIL XV 4577; 4579) para distinguir variaciones en los rasgos del recipiente, o bien para señalar un estado intermedio o de transición entre las dos formas, o como algo menos o más desarrollado de la forma genuina.

\section{HISTORIA DE LA CLASIFICACIÓN DESPUÉS DE DRESSEL}

La tabla tipológica de CIL XV no fue tenida en cuenta por los arqueólogos durante las décadas iniciales del siglo xx. Los trabajos de Siegfried Loeschcke (1909; 1942) en Germania con el material de las excavaciones de los campamentos militares de Haltern y Oberaden tuvieron bien presentes las ánforas roma-

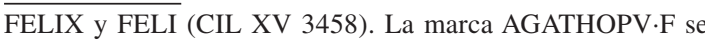
ha localizado recientemente en la bahía de Cádiz, donde está clasificada como ánfora vinaria itálica, pero se excluye el entorno campano-lacial ante la ausencia de los característicos desgrasantes volcánicos (Bernal et alii 2005: 210). Un sello FELIX en cuello de ánfora indeterminada aparece catalogado en CIL XI 6995,42 con un origen de Toscana (inter Cecina et le Ferriere). Conforme a esta escasez de datos, sugerimos con cautela entender la Dressel 4 como una forma itálica afín a la hegemónica Dressel 3 campana, con vidas paralelas, pero con un origen peninsular diferente. Tal vez haya que ver en el factor regional la variabilidad de sus rasgos formales que llevó a Dressel a crear dos grupos diferentes y afines.

${ }^{9}$ Se trata de un ánfora alta y cilíndrica acorde al diseño más evolucionado de la Dressel 2 (Figura 8). Dos buenos ejemplos para salir de dudas sobre la tipología asociada al sello NP son el ánfora completa del Estagnon (Fos-Sur-Mer) (Marty y Zaaraou 2009: 409, fig.13.1), y el ánfora del pecio Ile-Rousse (Alta Córcega) datado hacia mediados del siglo I d.C. (Sciallano y Liou 1985: 108). nas, pero bajo otro criterio mucho más genérico de clasificación basado en denominaciones locales que englobaban toda la cerámica romana recuperada en estos yacimientos. Del trabajo de Haltern se deduce la presencia de ánforas Dressel 2-4 en el tipo 66, las que presentan un asa geminada, donde se encuentran algunos ejemplares de origen tarraconense por las descripciones de las pastas (González Cesteros 2014: 161). En el campamento de Oberaden, ocupado con anterioridad a Haltern entre 11-8/7 a.C., se utilizó la forma 78 para designar a estos envases, tratándose de importaciones bastante tempranas de Dressel 2-4, quizá con presencia de las primeras producciones tarraconenses ${ }^{10}$. Las tres formas del grupo Dressel 2-4 también tuvieron otras denominaciones locales durante esa época inicial, con correspondencias del tipo Hofheim 73, Pompeii 12 y 35 (CIL IV, supp., tab. I-III), Camulodunum 182 y 182 b, Caerleon 79 y 80.

Albert Grenier fue el primer investigador francés en mostrar interés científico por la clasificación tipológica del CIL XV. En su síntesis general sobre las ánforas romanas toma en consideración la tabla de Dressel para señalar aquellos testimonios hallados en las provincias occidentales con sus contextos arqueológicos (Grenier 1934: 635-642). Además de reconocer en el tipo 1 de Dressel el ánfora itálica de vino por excelencia de edad republicana, agrupa las formas 2, 3, 4 y 5 sumando los hallazgos de Augst, Cartago, Haltern y Pompeya, con dataciones de finales de la República hasta mediados del Imperio.

Nino Lamboglia fue crítico con la tabla de CIL $\mathrm{XV}$ al sugerir a los arqueólogos su rechazo como modelo de clasificación general (Lamboglia 1955: 243-244). Por un lado, censuraba su parcialidad, que no estuviera completa con las formas ausentes que habían sido posteriormente añadidas, primero por Pelichet (formas del $n^{\circ} 46$ al 50; Pelichet 1946), y después por Almagro (hasta la forma 57; Almagro 1951: 105 y ss.). Luego, y no le faltaba razón, reprochaba las numerosas duplicaciones de números que señalaban a formas afines, más propias de ser consideradas variantes de una misma clase de ánfora, tal y como hemos podido comprobar en el apartado anterior sobre Castro Pretorio. Con la idea de poner en manos del investigador un instrumento de clasificación mejorado, rehace la tabla de CIL XV, pero con poco éxito. Lamboglia unifica los tipos afines, suprimiendo los números superfluos y organizando las formas por cronologías. Agrupa los números 3 y 2

\footnotetext{
${ }^{10}$ En los trabajos del material anfórico de Oberaden posterior a la II Guerra Mundial no se han encontrado Dressel 2-4 tarraconenses (González Cesteros 2014: 201; González Cesteros y Tremmel 2013).
} 
por un lado, y el 4, 5, 36, 44 y 45 por otro, pero concibiendo erróneamente estos últimos como resultado de la evolución de los dos primeros. Acierta con el orden 3 y 2 de las formas vinarias del primer grupo basándose en criterios evolutivos deducibles por las dimensiones de estos envases, pero se equivoca con la cronología de la forma 3 , que el autor sitúa ya desde el siglo II a.C., bastante alejada del momento inicial de la producción itálica en época de Augusto. Este desajuste cronológico confundió a investigadores de la talla de Fernand Benoît, que consideraba las Dressel 2-3 como ánforas republicanas de marcada tradición greco-itálica y con vida propia hasta el comienzo del Imperio (Benoît 1957: 256-258).

La agrupación de las tres formas que han dado nombre a la "Dressel 2-4" se detecta, por primera vez, en la obra de Callender (1965: 9-14, "Form 2"). Su criterio se basa en la apariencia general de los tres envases afines, con un apartado descriptivo demasiado general, si bien presta la debida atención a la cronología de los materiales. Tras analizar tanto las fechas de las inscripciones pintadas de Roma, Pompeya y Cartago, como los contextos de yacimientos terrestres en Germania y Britania, ofrece un horizonte cronológico mucho más amplio y preciso que arranca en la segunda mitad del siglo i a.C. y perdura sobrepasado el primer cuarto del siglo II d.C.

El arqueólogo e historiador italiano Fausto Zevi publica en 1966 una excelente síntesis sobre la tabla tipológica de CIL XV. Siguiendo el orden de la numeración de Dressel, revisa minuciosamente los datos epigráficos con el triple objetivo de determinar la cronología, la procedencia y el contenido de las ánforas. El autor estudia bajo el mismo epígrafe las formas 2, 3, 4 y 5 de Dressel (Zevi 1966: 214-217). Por las dataciones consulares llega a la conclusión de que se trata de cuatro envases análogos, que pertenecieron a una misma época histórica, con el momento comercial más floreciente entre Augusto y Tiberio ${ }^{11}$. Considera la forma 5 más alejada de las otras tres por su diseño peculiar y porque las inscripciones son normalmente en griego. Entiende las formas 2, 3 y 4 como variantes de una misma familia de ánforas por sus numerosos rasgos en común, pero también observa mayor diversidad de matices (epigrafía, arcilla, dimensiones, peso) respecto a lo señalado por

\footnotetext{
${ }^{11}$ Sin olvidarse de los tituli 4618 y 4585 en Dressel 3 similis, con dataciones consulares demasiado distantes entre sí, polarizadas con los años 27 a.C. (ánfora con inscripción griega de Castro Pretorio) y 146 d.C. (ánfora hallada "in agro Verano" en Roma). Dressel no encontró dataciones consulares en la forma 5, bien que Zevi sugiere leer el nombre del cónsul del año 12 a.C. o 3 d.C., L. Volusius Saturninus, escrito aislado en caso genitivo sobre los dos ejemplares de CIL XV 4646.
}

Dressel. En cuanto al origen de estas tres ánforas, su impresión resulta contrariada por el hecho de que tanto la forma 2 como la 3 hubiesen envasado los mismos vinos de Campania, Provenza y Tarraconense. Zevi justifica este hecho, aparentemente insólito, con el fenómeno de las imitaciones de ánforas en Galia e Hispania, donde se copiaron los contenedores de los prestigiosos vinos itálicos, aquellos de Campania en particular, para colocar los productos provinciales en los principales mercados consumidores del Mediterráneo. Al referirse al cuadro tipológico revisionista de Lamboglia, está de acuerdo en considerar las formas 3 y 2 como variantes complementarias para un mismo fin económico, pero le reprocha su incoherente horizonte republicano y no haber atendido las dataciones consulares de Dressel.

El trabajo revisionista de Zevi marcó un antes y un después en la manera de concebir esta familia de ánforas vinarias. Sus indicaciones sirvieron de guía a los investigadores posteriores para mejorar el estudio de estos materiales desde diferentes puntos de vista (Beltrán 1970: 358-380; Vegas 1973: 125). Con el paso del tiempo se han ido sumando nuevos datos de yacimientos terrestres y submarinos, lo que ha permitido comparar contextos cerámicos, haciendo posible conocer los orígenes y la vida de estos recipientes con una visión económica y social cada vez más detallada y compleja.

Hasta aquí este rápido repaso historiográfico sobre las clasificaciones después de Dressel de las formas 2, 3 y 4 de CIL XV. Tras los trabajos de Callender y Zevi, esta agrupación se convirtió en un denominador común, fosilizándose el nombre "Dressel 2-4" hasta nuestros días, como un término popular de clasificación empleado habitualmente por la investigación en su sentido más amplio.

\section{3. "DRESSEL 2-4 TARRACONENSE": ORIGEN Y CRITERIOS DE CLASIFICACIÓN}

En el primer apartado hemos visto cómo la versión layetana de las formas 2 y 3 se detectó, por primera vez, al estudiar Dressel el material de Castro Pretorio, donde se localizaron tres ánforas con tituli picti que mencionaban el afamado vino de Lauro (Figura 2) recordado por los clásicos entre los mejores caldos de Hispania (Plinio N.H. XIV 71). Igualmente, descubrimos en dicho depósito otras inscripciones sobre vinos layetanos, escondidas detrás de unas fórmulas epigráficas diferentes, menos explícitas, sin la denominación de origen del vino, mucho más difíciles de detectar si se desconoce la zona de producción de los sellos asociados a estas ánforas. La identificación del 
vinum Lauronense desde los tiempos de Dressel fue la pista más fiable para rastrear los vinos hispanos por el Mediterráneo. Posteriormente se fueron sumando a esta lista los hallazgos de Pompeya (CIL IV 5558), Cartago (Delattre 1906) y Ostia (Panella 1970: 111 y 131-133). Pero tuvieron que pasar muchos años hasta que André Tchernia y Ricardo Pascual dieran a conocer los lugares de fabricación de estos materiales en Cataluña.

André Tchernia entró en contacto directo con estos materiales en septiembre de 1969 durante una estancia científica llevada a cabo en Cataluña (Tchernia 1971). Los investigadores locales le abrieron las puertas de los museos de Ampurias, Barcelona, Caldes de Montbui, y Mataró. En el primer apartado de su memoria científica describe las ánforas "fuselées de Léétanie", hoy llamadas Pascual 1, la predecesora de la Dressel 2-4 layetana, definida como un nuevo tipo de envase vinario por Ricardo Pascual en 1960 (Pascual 1962). El segundo apartado lo dedica a la "Dr. 2-4 de Tarraconaise", y es a partir de ese momento cuando esta terminología se empleará de un modo generalizado para clasificar las ánforas de vino altoimperiales producidas a lo largo de la fachada mediterránea de esta provincia romana.

Tchernia entiende las Dressel 2-4 como imitaciones de los prototipos griegos de Cos (Grace 1961). Revisando el material anfórico de Caldes de Montbui descubre que los mismos hornos de las ánforas Pascual 1 habían producido igualmente Dressel 2-4, y que esta última se dejaba ver en mayor cantidad. En el Museo de Mataró vuelve a encontrar las dos tipologías asociadas entre el material del alfar de $L$. Volteilius localizado en el yacimiento de Sot del Camp (Sant Vicenç de Montalt). Pero en esta ocasión acompañando a un tercer tipo de ánfora de cuerpo ovoide, que se definiría más adelante como Layetana 1 o Tarraconense 1 (Comas 1985; Nolla y Solías 1984), para un fase de producción anterior a la Pascual 1 ya en plena época tardorrepublicana. Al estudiar las ánforas Dressel 2-4 con sellos TIBISI y ANTH descubre que el fenómeno productivo sobrepasaba los límites territoriales de la franja layetana, siendo más extenso y con un carácter multiregional, que alcanzaba por el sur la provincia de Tarragona y por el norte el territorio de Ampurias. La producción de ánforas en estas otras zonas se mostraba igualmente diversificada, pero con la novedad de introducir recipientes para conservas de pescado que imitaban algunas formas de la extensa familia Dressel 7-11 de la Bética.

En cuanto a las Dressel 2-4 tarraconenses, Tchernia observa variabilidad formal en los acabados, tanto a nivel local como entre áreas productoras, con múltiples y no siempre comunes variantes de labios (simple, redondeado, alto y plano, triangular) y asas (bífidas, semibífidas). Algunos rasgos típicos del material hispano estaban ausentes en las producciones de Italia, pudiendo este detalle resultar de utilidad para diferenciar el origen geográfico de las ánforas halladas en los mercados de consumo. Finalmente, el autor hace una oportuna y necesaria síntesis sobre la cronología de estas ánforas en Cataluña. Sitúa el comienzo de la producción de Dressel 2-4 en un momento tardoaugusteo subsiguiente a aquel de la Pascual 1. Toma el horizonte preflavio de Castro Petrorio como uno de los momentos más tardíos, y sugiere situar la época de apogeo de las exportaciones de vino tarraconense a Roma y Cartago durante la primera mitad del siglo I d.C.

Un año después, en 1972, Tchernia y Zevi publicaron conjuntamente una detallada síntesis sobre la presencia de las ánforas Dressel 2-4 de la Tarraconense y de Campania en Ostia. Los autores se percatan de la importancia del estudio de la arcilla para distinguir el origen geográfico de los recipientes afines. En este trabajo llegan a caracterizar fácilmente la pasta más corriente de una parte de las ánforas fabricadas en Cataluña, aquella dura y rojiza ("rouge brique très frane") con abundante desgrasantes de cuarzo, bien visible en superficie, la que caracteriza a las producciones de la Layetania oriental (Figura 6). También ven, sin conocer entonces el origen de muchos sellos de la Layetania occidental, la otra pasta característica, con un componente arcilloso diferente, gris o marrón, con engobe claro y color crema. Por otro lado, los contextos de Ostia confirmaban el horizonte cronológico que ya había sugerido Tchernia. La mayor concentración de materiales tarraconenses se daba en niveles arqueológicos de Tiberio y Claudio. Entre Tiberio y los Flavios los vinos tarraconense y campano fueron consumidos "côte à côte" en Ostia, bajo una disputada concurrencia comercial entre provincias, sin que la presencia de uno provocara la desaparición del otro. A partir del final del siglo I d.C. los testimonios materiales en Ostia son inciertos y casi contradictorios.

El estudio de las ánforas de Ostia puso al descubierto los problemas relacionados con la identificación y clasificación de las ánforas Dressel 2-4 por áreas de producción. El análisis se veía limitado por el hecho de tomar los datos en los mercados consumidores de los vinos, en lugar de hacerlo directamente de las alfarerías. Bajo tales condiciones de trabajo, las afinidades entre las formas 2 y 3 hacían casi imposible establecer criterios tipológicos para distinguir los envases itálicos, tarraconenses y narbonenses (Tchernia y Zevi 1972: 35). A la vista del problema, pocos años más tarde, hubo un intento fallido de elaborar un 
sistema objetivo de clasificación basado en fórmulas matemáticas que, mediante un algoritmo, se ponía en relación métrica las diferentes partes del ánfora Dressel 2-4 (Farinas del Cerro et alii 1977). La elección aleatoria de unos materiales que rara vez se conservan completos en los yacimientos terrestres dio lugar a una aplicación incapaz de establecer conclusiones positivas sobre tipología, origen y cronología.

En el año 1974 se celebró en Roma el coloquio internacional Méthodes classiques et méthodes formelles dans l'étude typologique des amphores, que tuvo gran repercusión científica, hasta el punto de asentar las bases metodológicas a seguir en el desarrollo de futuros trabajos sobre tipología y caracterización de las producciones anfóricas romanas en general ${ }^{12}$. El acto contó con la participación del investigador catalán Ricardo Pascual Guash, precursor del estudio de las ánforas de la Layetania y su epigrafía asociada. Con su ponencia se puso de manifiesto la importantísima producción alfarera layetana, con verdaderas industrias cerámicas dedicadas a la fabricación de ánforas Pascual 1 y Dressel 2-4, con una riqueza epigráfica de sellos y grafitos considerable (Pascual 1977). Pascual se vale entonces de la agrupación Dressel 2-3 de Lamboglia para identificar los materiales hallados en Cataluña, sin dar directrices claras sobre cómo diferenciar estas dos formas afines entre sí, describiendo sus rasgos vagamente con la mera intención de distinguirla de la Pascual 1.

En el año 1985 se publica el mayor estudio monográfico sobre pecios con cargamento de Dressel 2-4 tarraconense en el Mediterráneo occidental (Sciallano y Liou 1985). Este trabajo marca un antes y un después en la investigación al incorporar importantes novedades que daban respuesta a algunas de las preguntas aquí planteadas con anterioridad. Al tratarse de conjuntos arqueológicos cerrados, los yacimientos submarinos proporcionan las cronologías más precisas con las que fechar las fases de actividad industrial de las alfarerías tomando en consideración la procedencia de los sellos. Por otro lado, se confirma el uso de las formas 2 y 3 de Dressel como envases vehiculares del comercio tarraconense durante el horizonte cronológico ya avanzado por Tchernia. En el siguiente apartado hablamos detenidamente sobre estos pecios con el fin de desvelar su valor clave para comprender y fechar el paso evolutivo de la forma 3 a la 2.

${ }^{12}$ A partir de ese momento se empezarán a publicar estudios locales de ánforas Dressel 2-4 en el País Valenciano (Aranegui 1981; Gisbert 1987), así como del área narbonense en el sur de la Galia (Laubenheimer 1989), dándose a conocer otras producciones de fabricación autóctona bien diferenciadas tipológicamente. Por poner en esta nota algunos ejemplos, ya que la bibliografía es mucho más abundante.
Desde esa última fecha hasta hoy, las publicaciones sobre Dressel 2-4 tarraconense no aportan novedades significativas en materia tipológica, sin que por ello desmerezca destacar los siguientes trabajos con variedad de enfoques metodológicos para la investigación. Cabe hablar en primer lugar de la obra de síntesis de Jordi Miró (1988) sobre las producciones de ánforas romanas en Cataluña. En ella se ponen por primera vez en orden, con una visión clara de conjunto, los datos arqueológicos, tipológicos y epigráficos, para analizarlos y confrontarlos en los procesos socioeconómicos del período histórico del comercio del vino tarraconense entre la Tardorrepública y el Alto Imperio.

La última revisión en materia tipológica se produce en el año 2008 a cargo de los investigadores Albert López Mullor y Albert Martín Menéndez (2008: 6475), mediante la elaboración de una síntesis general detallada para cada uno de los tipos anfóricos producidos en el actual territorio de Cataluña. Su finalidad es tratar de definir seriaciones detalladas de variantes para cada entidad tipológica (Tarraconense 1, Pascual 1, Dressel 2-4), ajustándolas con las dataciones de los contextos arqueológicos fiables. El estudio de la Dressel 2-4 no hace sino reafirmar parte de lo ya expuesto hasta ahora. Los autores descartan la forma 4 por falta de testimonios dentro del material estudiado, y consideran más correcto llamarlas Dressel 2-3. Describen por separado las características físicas de las formas 2 y 3 , pero al hablar de cronología y difusión las incluyen como un solo grupo Dressel 2-3, como dos envases coetáneos y alternativos, sin reparar en el factor evolutivo del paso de la forma 3 a la 2.

Una visión parecida se ofrece en el trabajo de síntesis de Piero Dell'Amico y Francisca Pallarés (2007) sobre las ánforas de la Layetania. Los autores también descartan la forma 4 de Dressel por falta de testimonios tarraconenses. Describen las formas Dressel 2 y 3 con este orden sin observar el factor evolutivo existente con la numeración inversa. Llaman Dressel 3 a la forma de aspecto más arcaico y Dressel 2-3 a nuestra forma 3 'clásica' (Figura 8) por entender sus rasgos como de transición entre las formas 2 y 3 de Dressel.

Cerramos este tercer apartado con la reciente publicación de Verónica Martínez Ferreras (2014), "Ánforas vinarias de Hispania Citerior-Tarraconensis (siglo I a.C. - I d.C.)", de indispensable consulta, al presentar el mapa arqueométrico más completo sobre las ánforas de vino en territorio catalán. Esta obra constituye un logro científico importante para futuras investigaciones, al permitir acceder y manejar información fiable, con datos tomados directamente del material cerámico en los centros de producción. 
Con la caracterización de estos materiales, la determinación de sus propiedades físicas y químicas, tenemos finalmente en nuestras manos un catálogo fundamental con el que distinguir las zonas de origen de las ánforas layetanas, y éstas a su vez de las áreas nordeste y suroeste del litoral de Cataluña.

\section{PECIOS CON CARGAMENTO TARRACO- NENSE: EL PASO DE LA DRESSEL 3 A LA DRESSEL 2.}

En el apartado anterior hemos subrayado la trascendencia científica que tuvo la publicación del estudio monográfico de Archaeonautica 5 para el desarrollo de esta línea de investigación, al ofrecer la lista más completa de pecios con cargamento de Dressel 2-4 tarraconense, cuyas cronologías siguen siendo el principal referente para datar los sellos y las fases productivas de las alfarerías. Además de confirmarse el uso exclusivo de las formas 2 y 3 de Dressel para transportar los vinos layetanos, existe otro detalle mucho más interesante que no ha sido tenido debidamente en cuenta: las formas 2 y 3 no coexisten en un mismo cargamento, por lo que deja de tener sentido la idea de dos envases coetáneos y alternativos para una misma misión comercial. En cada pecio con Dressel 3 o Dressel 2 la homogeneidad tipológica es absoluta con diferencias mínimas en los acabados (Figura 3). Por lo tanto, la cuestión tipológica se resuelve con la evolución de estas ánforas. El paso de la forma 3 a la 2 se percibe poniendo en relación la forma del recipiente con las dataciones de los pecios (Figura 4).

Repasando Archaeonautica 5 vemos cómo la forma 3 se data dentro de un horizonte tardoaugusteo y tiberiano en los pecios de Dramont B, Sud-Lavezzi 3, Planier 1, Chrétienne H, Diano Marina (¿mediado siglo I d.C.?), Perduto 1. Por otro lado, la forma 2 se fecha básicamente en época julio-claudia con los pecios de Petit-Congloué, Grand-Rouveau, Fourmigues, Ile-Rousse, Cavallo 1, Est-Perduto, Barà, Cala Vellana. Tan sólo existe un fleco con la insólita datación tardía de Diano Marina sobre la que hablamos más adelante.

En los últimos años se han dado a conocer más cargamentos con ánforas tarraconenses, que confirman y refuerzan lo dicho hasta ahora sobre la evolución de las dos formas y sus cronologías sucesivas. La forma 3 aparece en Grand Ribaud D con fecha $c a$. 9-1 a.C. (Hesnard et alii 1988), La Giraglia en ca. 20 d.C. (Sciallano y Marlier 2008). La forma 2 la encontramos en el pecio flavio de Marina di Fiori con ánforas de posible origen en el territorio de Tarraco (Bernard 2007).
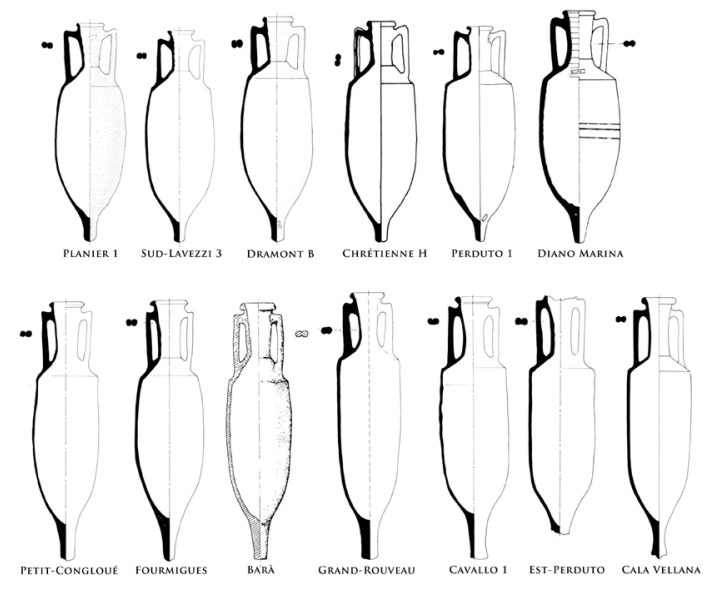

Figura 3. Ánforas de la forma 3 (arriba) y forma 2 (abajo) en Archaeonautica 5.

Cabe a continuación analizar la fecha conflictiva del pecio de Diano Marina (Pallarés 1983; 1985; Sciallano y Liou 1985: 95-107; Dell'Amico y Pallarés 2005). Su datación hacia mediados del siglo I d.C. resulta imposible por la presencia de ánforas Dressel 3 , si se acepta nuestro modelo descriptivo (Figura 8), donde la forma 2 sustituye a la anterior en $c a .30$ d.C. Tomar la datación tardía de Diano Marina equivaldría a decir que la forma 3 llegó a ser contemporánea de la 2. Este argumento no se sostiene porque los pecios con ánforas tarraconenses jamás combinan las formas 3 y 2 en un mismo cargamento, al tratarse de dos variantes de la misma clase de objeto fabricadas en distintas épocas (Figura 4).

La fecha de Diano Marina se basa, en particular, por el estudio de la cerámica de paredes finas y la sigillata itálica de la dotación de abordo de la nave. El repertorio epigráfico de las ánforas layetanas es originario de la zona productora del Baix Llobregat, pero los sellos carecen de paralelos claros y bien datados para confirmarla o desmentirla. Tampoco se puede precisar con los sellos en dolia, caso de los Piranii de Minturno, a quienes conocemos en otros naufragios con ánforas Dressel 3 o Dressel 2 layetanas, debido al uso prolongado de estos contenedores en las naves "cisterna" durante unos cincuenta años.

Sin embargo, cabe tener en cuenta el siguiente análisis revisionista para bajar la cronología de Diano Marina a un momento anterior, en el primer cuarto del siglo I d.C. La presencia de ánforas Dressel 9 con rasgos afines a las recuperadas en el pecio Sud Lavezzi 1 (Liou y Domergue 1990: 141-142, 153) apunta a una fecha ante quem 25 d.C. El sello in planta pedis de Sextus Villius Natalis sobre TSI aporta 


\begin{tabular}{|l|c|l|l|l|}
\hline \multicolumn{1}{|c|}{ Pecio } & Forma & \multicolumn{1}{c|}{ Origen } & \multicolumn{1}{c|}{ Datación } & \multicolumn{1}{c|}{ Bibliografía } \\
\hline Grand Ribaud D & 3 & Baix Llobregat & ca. 9-1 a.C. & Hesnard et alii 1988 \\
\hline Dramont B & 3 & Baix Llobregat & primeros años s. I d.C & Sciallano y Liou 1985: 71-77 \\
\hline Planier 1 & 3 & Layetania occidental & ca. 15 d.C. & Sciallano y Liou 1985: 17-25 \\
\hline Chrétienne H & 3 & Baix Llobregat & $c a .15-25$ d.C. & Sciallano y Liou 1985: 78-94 \\
\hline La Giraglia & 3 & Baix Llobregat & ca. 20 d.C. & Sciallano y Marlier 2008 \\
\hline Diano Marina & 3 & Baix Llobregat & ¿med. s. I d.C.? & Sciallano y Liou 1985: 95-107 \\
\hline Sud-Lavezzi 3 & 3 & Baix Llobregat & primer cuarto s. I d.C. & Sciallano y Liou 1985: 130-144 \\
\hline Perduto 1 & 3 & Layetania oriental & - & Sciallano y Liou 1985: 145-147 \\
\hline Petit-Congloué & 2 & Layetania occidental & julio-claudia & Sciallano y Liou 1985: 26-43 \\
\hline Grand-Rouveau & 2 & Baix Llobregat & julio-claudia & Sciallano y Liou 1985: 44-65 \\
\hline Fourmigues & 2 & Layetania occidental & - & Sciallano y Liou 1985: 66-70 \\
\hline Ile-Rousse & 2 & Layetania oriental & julio-claudia & Sciallano y Liou 1985: 108-118 \\
\hline Cavallo 1 & 2 & Layetania oriental & julio-claudia & Sciallano y Liou 1985: 119-129 \\
\hline Est-Perduto & 2 & Baix Llobregat & primera mitad s. I d.C. & Sciallano y Liou 1985: 148-152 \\
\hline Barà & 2 & $\begin{array}{l}\text { supuestamente del } \\
\text { territorio de Tarraco }\end{array}$ & - & Sciallano y Liou 1985: 153-154 \\
\hline Pointe Lequin 3 & 2 & - & Nerón & $\begin{array}{l}\text { Gallia Informations, Recherches } \\
\text { sous-marines, I. 1987-1988: 35 }\end{array}$ \\
\hline Cala Vellana & 2 & Layetania oriental & 40-60 d.C. & Sciallano y Liou 1985: 155-157 \\
\hline Marina di Fiori & 2 & $\begin{array}{l}\text { Quizá del territorio de } \\
\text { Tarraco }\end{array}$ & flavio & Bernard 2007 \\
\hline
\end{tabular}

Figura 4. Tabla- resumen de pecios con ánforas tarraconenses producidas en Cataluña agrupados por las formas 3 y 2 de Dressel.

una datación de 15-40 d.C. (OCK. 2429/2430). El otro sello sobre TSI del alfarero $\operatorname{Mur}(r) i(u s)$ se data in planta pedis entre 15-30 d.C. (OCK 1202). Entre las cerámicas dibujadas hay una copa Consp. 26.2 (datada del 1-50 d.C.) y un plato del tipo Consp. 18/19 (15 a.C-30 d.C.). Viendo estos datos pensamos que el conjunto, según la sigillata, debería ser a lo sumo del 15-30 d.C.

\section{CARTAGO: DINÁMICA COMERCIAL DE LOS VINOS TARRACONENSES CON LAS FORMAS 3 Y 2}

En el primer apartado sobre Castro Pretorio hemos comprobado la importancia de la epigrafía anfórica (sellos, grafitos, tituli picti) para localizar posibles recipientes tarraconenses en una de las colecciones más antiguas de Roma. Jordi Miró (1988: 311-312) y Joann Freed (1998) hicieron algo parecido con el material del segundo muro de ánforas descubierto en Cartago, dado a conocer por el arqueólogo francés Alfred Louis Delattre en 1906.

Este segundo muro fue levantado con más de 2.000 ánforas. Las fechas consulares de las inscripciones pintadas conservadas dieron un horizonte cronológico del segundo cuarto del siglo i d.C. similar al de Castro Pretorio. Delattre (1906: 36, fig. 2) reproduce hasta 20 recipientes cerámicos diferentes, con un predominio notable de ánforas de vino sobre las de aceite y garum, muchas de ellas de origen oriental, entre las que se reconocen también las formas 2 y 3 de la tabla de Dressel (Figura 5).

Sabemos por Freed que las ánforas de vino tarraconense estaban holgadamente representadas en el muro de ánforas, habiéndose conservado 108 ejemplares en las colecciones del Museo Nacional de Cartago. Los tituli picti publicados por Delattre se han desvanecido de la superficie del ánfora, pero la autora reproduce con nuevos calcos la mayor parte de los sellos impresos en los materiales del museo. Del examen de todos los datos epigráficos publicados hasta hoy se pueden extraer las siguientes observaciones generales sobre el consumo de los vinos de la Tarraconense en Cartago.

Las ánforas tarraconenses de Cartago tienen un origen geográfico variado y disperso por el actual territorio de Cataluña, con mayoría abrumadora de envases layetanos frente a una discreta presencia confirmada de vinos de Tarraco para un momento más tardío (Berni 2010). La mayor parte de los sellos documentados aparecen impresos en la forma Dressel 
2 de edad julio-claudia, que Freed reproduce en su trabajo con varios dibujos (Figura 5). La epigrafía sobre Dressel 2 está capitalizada por ánforas de la Layetania oriental (AP, ASB, L·M·N, LMNO, LMO + SELE, MAX, NP, PTE), la vertiente costera que daba salida al prestigioso vino Lauronense (Figura 6). Por debajo de esta cifra quedan los otros sellos en ánfora Dressel 2 de la Layetania occidental (AMANDI, LLC, S·?), así como la comentada presencia de vinos del Ager Tarraconensis (LCM + P, CE, IR). La dinámica comercial funciona en sentido contrario con la forma Dressel 3 de la etapa anterior en tiempos de Tiberio. Los sellos asociados a la forma Dressel 3 son, prevalentemente, de la Layetania occidental (AD, AMP + OPT, CLAS + OPT, CELS, QVA, Q·V·G), con un número de casos muy superior al constatado para la Layetania oriental (MAR, S.L.L), y sin rastro de inscripciones de la región de Tarraco.

A nuestro modo de ver, esta alternancia geográfica en el tiempo tiene una explicación económica, cuyas causas y consecuencias hay que buscarlas en el devenir y el dictado de los grandes mercados consumidores. Durante el primer cuarto del siglo I d.C. es la zona de Barcino, con sus industrias en el Baix Llobregat (Berni 2015) la que acapara el protagonismo comercial con el mayor volumen de las exportaciones, colocando sus abundantes vinos "layetanos", más baratos y de modesta calidad. Posteriormente, ya en época julio-claudia y con la Dressel 2, el modelo anterior de negocios con la disyuntiva "cantidad por encima de calidad" deja de ser rentable económicamente. Para contrarrestar la crisis del vino barato para el consumo, productores y comerciantes apuestan más decididamente por los vinos de óptima calidad, viéndose beneficiados las plantaciones de viñas y los fabricantes de ánforas en la Layetania oriental. Este cambio de estrategia de mercado se percibe igualmente con la información de Castro Pretorio (Figura 2) y los pecios con ánforas layetanas (Figura 4), donde los productos de la vertiente oriental se dejan ver con mayor frecuencia en la Dressel 2. Recordemos, una vez más, el pasaje de Plinio (N.H. XIV 71): "Hispaniarum Laeetana copia nobilitantur, elegantia vero Tarraconensia atque Lauronensia et Balearica ex insulis conferuntur Italiae primis". En tiempos de Plinio el Viejo (23-79 d.C.), los vinos tarraconenses de prestigio eran el Lauronense (Layetania oriental) y el de Tarraco (Marcial XIII 118; Silio Itálico III 369-370 y XV 176-177; Floro, Vergilius orator an poeta II, 8), mientras el llamado vino "layetano" (Layetania occidental) que se consumía en Roma se clasificaba entre los más modestos, baratos, e "infames" (Marcial, I 26; VII 53, 6; XIII 118).

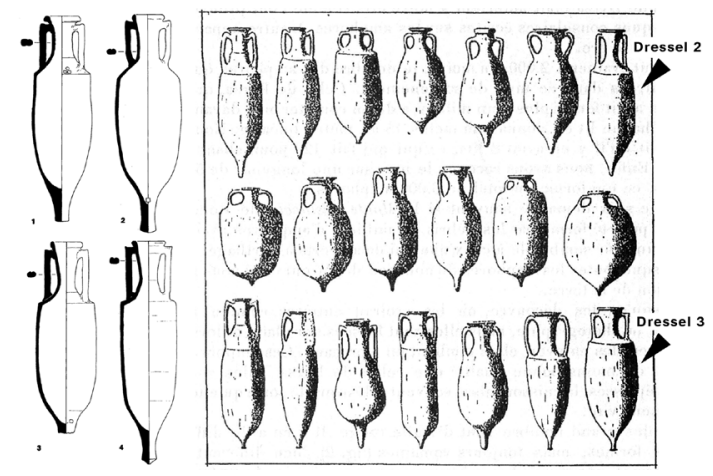

Figura 5. Izquierda: cuatro ánforas Dressel 2 de Cartago dibujadas por Freed. Derecha: ánforas del segundo muro dibujadas por Delattre.

\section{HACIA UN NUEVO MODELO CRONO-TIPO- LÓGICO}

Tras este amplio repaso historiográfico sobre el origen de la investigación y los criterios de clasificación tipológica de la "Dressel 2-4 tarraconense" hemos llegado a las siguientes deducciones:

- La adopción científica del nombre canónico "Dressel 2-4 tarraconense" se lo debemos al trabajo pionero de André Tchernia del año 1971, influenciado entonces por las clasificaciones generales de Callender y Zevi.

- Este término se halla fosilizado en la actualidad. Se emplea con un sentido amplio y ambiguo, sin apenas prestar atención en los detalles formales de las ánforas.

- El estudio de las ánforas de Castro Pretorio, Cartago y los pecios con cargamento tarraconense ha puesto de manifiesto el uso exclusivo de las formas 2 y 3 de Dressel, y el rechazo de la forma 4 por falta de testimonios claros.

- La forma 3 se data con anterioridad a la forma 2. No son dos recipientes diferentes, coetáneos y alternativos para transportar vino, sino la misma cosa como resultado de un proceso evolutivo que cubre, grosso modo, toda la primera mitad del siglo i d.C.

- La Layetania occidental acaparó el mayor volumen de las exportaciones en Dressel 3, y la oriental en Dressel 2. La dinámica comercial entre estas dos zonas productoras de vino se invirtió por la coyuntura "calidad versus cantidad" en el segundo cuarto del siglo I d.C.

Cabe a continuación poner sobre la mesa una serie de consideraciones sobre algunos interrogantes que se dan en el actual estado de la investigación y que 
debemos abordar antes de trazar el primer cuadro evolutivo para las ánforas layetanas (Figura 8).

En el estado inicial de la investigación, Tchernia percibió la magnitud geográfica del fenómeno productivo en Cataluña que sobrepasaba los límites de la Layetania, alcanzando los territorios de Tarraco y Emporiae. Además, con excelente intuición, observó variedades de rasgos en los acabados que podían deberse a factores socioculturales propios de cada zona productora. Aún así, comedido en ese nuevo escenario científico, se decantó por el nombre genérico "tarraconense" para adjetivar a todos estos recipientes. En la actualidad, los avances científicos han superado con creces las expectativas iniciales. Gracias a los aportes de la arqueología, la sistematización de la epigrafía y el mapa arqueométrico recién finalizado por Martínez Ferreras, estamos en condiciones inmejorables para redefinir con criterios histórico-regionales las distintas producciones anfóricas de Cataluña. Por este motivo, somos partidarios de hacer uso exclusivo del apelativo "layetano" para etiquetar las ánforas producidas en la franja costera central de Cataluña, entre los ríos Llobregat (al sur) y Tordera (al norte). Además, la atribución regional "layetana" nos permite rastrear mejor sus datos con la subdivisión que hemos hecho del territorio en dos áreas geográfica con la economía del vino polarizada. Sugerimos pues acotar el alcance geográfico que pesa actualmente sobre el adjetivo "tarraconense" con valor de provincia y nos decantamos por entenderlo como denominación regional de "vino de Tarraco", tal y como ha defendido Ramon Járrega en reiteradas ocasiones al estudiar las ánforas del Ager Tarraconensis (Járrega 2008: 100).

La segunda consideración atañe a las edades de las formas 3 y 2 de Dressel. La revisión de los datos

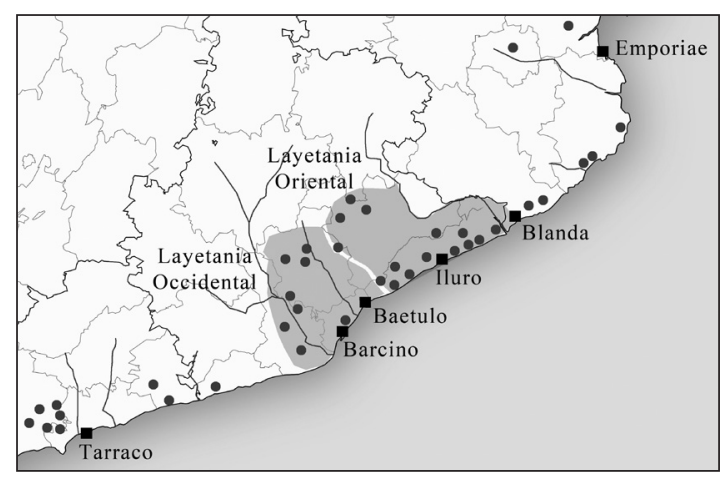

Figura 6. Regiones productoras de ánforas vinarias entre Tarraco y Emporiae. Al centro la Layetania subdividida en sus dos vertientes oriental (El Maresme y Vallés Oriental) y occidental (Barcelonés, Baix Llobregat, Vallés Occidental) de Castro Pretorio y Cartago pone de manifiesto la mayor presencia de Dressel 2 por ser este envase el de edad más avanzada. El orden 3-2 y su división cronológica en los últimos años del reinado de Tiberio se confirma agrupando las formas por las dataciones de los pecios. La supuesta contemporaneidad entre estas dos formas está descartada al no existir mezcla de envases en un mismo cargamento. Las formas 2 y 3 son, en realidad, la duplicación de la misma clase de objeto, por lo que deberíamos utilizar letras (A, B), en lugar de números, para distinguirlas como variantes evolutivas. Todos estos detalles tienen especial importancia para comprender los límites funcionales de la tipología de Dressel, pudiendo ser útiles para el análisis crítico de otros modelos de clasificación posteriores basados en la tabla de CIL XV.

La tercera reflexión, no menos importante, concierne al concepto de imitación cuando se utiliza, desafortunadamente, con un sentido amplio. Por ejemplo, al afirmar que las Dressel 2-4 tarraconenses copian los modelos itálicos. A nuestro modo de ver, esta idea, que ya fue sugerida por Zevi, es correcta pero carece de precisión y profundidad para una perfecta comprensión del caso. Por lo hasta aquí expuesto, existen argumentos de peso para afirmar que el fenómeno de las imitaciones en la Layetania nace con la Dressel 3 en los últimos años antes del cambio de era. La forma evolucionada Dressel 2 debe ser entendida de manera diferente, no como imitación itálica, más bien como recipiente autóctono optimizado con mayor carga identitaria regional. Su afinidad formal es menor respecto a la Dressel 2 itálica o gala de época julio-claudia, y obedece, hasta cierto punto, a unos estándares estéticos y funcionales globalizados, impuestos por un mercado interprovincial altamente exigente y competitivo. Lo contrario ocurre con las primeras producciones de Dressel 3 layetana en época tardoaugustea, mucho más difícil de distinguir por criterios meramente tipológicos de su homóloga campana ${ }^{13}$ : labio pequeño y redondeado; asas de codo redondeado, siempre bífidas formadas por dos tiras de arcilla enganchadas por un costado, antebrazo oblicuo; cuerpo bajo y abombado; doblemente carenadas en hombro y cuello; pivote de pequeño tamaño (Figura 7).

\footnotetext{
${ }^{13}$ Las primeras imitaciones de Dressel 3 layetana son similares a las ánforas campanas de los barcos cisterna de Grand Ribaud D (Hesnard et alii 1988: 61 ss.) y Ladispoli (Gianfrotta y Hesnard 1987: 285-286), dos naufragios datados en torno al cambio de era. En Pompeya se clasifican con los subtipos 1 y 2 de Panella y Fano (1977: 149). Son famosas las producciones pompeyanas de L. Eumachius y M. Livius Causorius.
} 

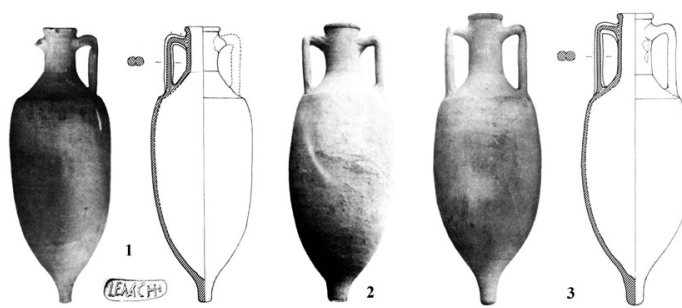

Figura 7. Ánforas Dressel 3 pompeyanas. Subtipos 1 y 2 de Panella y Fano (1977: 165) datados en los últimos años antes del cambio de era.

Presentamos a continuación el primer esbozo crono-tipológico del ánfora layetana altoimperial (Figuras 8 y 9), con la finalidad de asentar las bases descriptivas para clasificar estos materiales por sus cronologías. El cuadro tipológico es aproximativo, mucho más conceptual que empírico. Será en futuros trabajos cuando abordaremos los datos descriptivos con mayor amplitud de miras. De momento, esperamos que sirva de ejemplo, que marque tendencias en la manera de segmentar la sucesión de las cuatro variantes evolutivas que sugerimos (A-D).

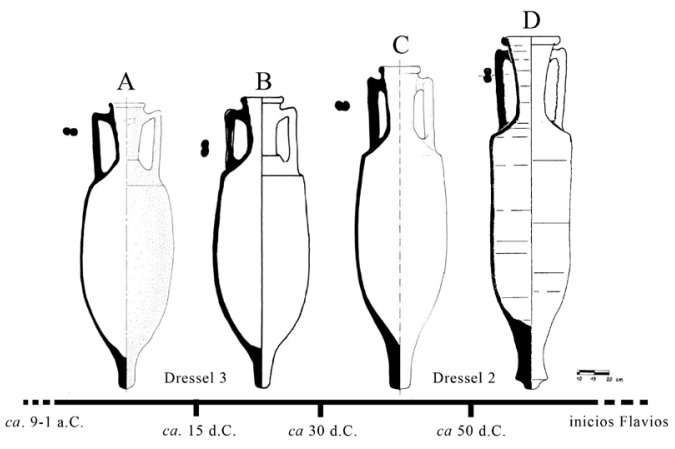

Figura 8. Primer borrador evolutivo para las ánforas vinarias altoimperiales de la Layetania.

Según nuestro modelo tipológico, el período de vida de los envases layetanos se sitúa entre los últimos años antes del cambo de era y el comienzo de la dinastía Flavia (Berni y Miró 2013: 75-81). Un hecho histórico de gran importancia que podría justificar su fulminante aparición, en sustitución y perjuicio del ánfora Pascual 1, sería la fundación de la colonia Barcino hacia ca. 15-9 a.C. Las primeras imitaciones layetanas (A) de la Dressel 3 campana tuvieron entre

\begin{tabular}{|c|c|c|c|c|}
\hline & $\begin{array}{c}\text { A } \\
\text { Dressel } 3 \text { temprana }\end{array}$ & $\begin{array}{c}\text { B } \\
\text { Dressel } 3 \text { clásica }\end{array}$ & $\begin{array}{c}\text { C } \\
\text { Dressel } 2 \text { clásica }\end{array}$ & $\begin{array}{c}\text { D } \\
\text { Dressel } 2 \text { tardía }\end{array}$ \\
\hline Métrica & \multicolumn{2}{|c|}{$\begin{array}{c}\text { Altura } 70 \text { - } 97,5 \mathrm{~cm} \text {; diámetro máximo } 29-36 \text {; } \\
\text { capacidad } 22,9 \text { - } 33,5 \text { litros; peso } 13-19,6 \mathrm{~kg} \text {; ratio } \\
\text { (c/p) } 1,53-2,19\end{array}$} & \multicolumn{2}{|c|}{$\begin{array}{c}\text { Altura } 97,5 \text { - } 107,5 \mathrm{~cm} \text {; diámetro máximo } 28-33 ; \\
\text { capacidad } 23 \text { - } 30 \text { litros; peso } 15 \text { - } 20 \mathrm{~kg} \text {; ratio (c/p) } \\
1,35-2\end{array}$} \\
\hline Borde & $\begin{array}{l}\text { Labio simple, con } \\
\text { tendencia redondeado, } \\
\text { a veces suavemente } \\
\text { marcado. Diámetro boca } \\
\text { de tamaño normal }\end{array}$ & $\begin{array}{l}\text { Más desarrollado. } \\
\text { Variabilidad de labios. } \\
\text { Diámetro boca de } \\
\text { tamaño normal }\end{array}$ & $\begin{array}{l}\text { Más desarrollado. } \\
\text { Variabilidad de labios. } \\
\text { Diámetro boca de } \\
\text { tamaño más grande }\end{array}$ & $\begin{array}{l}\text { Redondeado y } \\
\text { engrosado. Diámetro } \\
\text { boca exageradamente } \\
\text { grande }\end{array}$ \\
\hline Cuello & $\begin{array}{l}\text { Corto y con tendencia } \\
\text { exvasado. Carena bien } \\
\text { marcada }\end{array}$ & $\begin{array}{l}\text { Corto y con tendencia } \\
\text { cilíndrico. Carena } \\
\text { marcada }\end{array}$ & $\begin{array}{l}\text { Más alto y con tendencia } \\
\text { cilíndrico. Suave carena }\end{array}$ & $\begin{array}{l}\text { Alto y bastante } \\
\text { exvasado. Carena } \\
\text { inapreciable }\end{array}$ \\
\hline Asas & $\begin{array}{c}\text { Antebrazo largo } \\
\text { y oblicuo. Codo } \\
\text { redondeado o en punta. } \\
\text { Asas bífidas, de longitud } \\
\text { mediana y caídas hacia } \\
\text { dentro }\end{array}$ & $\begin{array}{c}\text { Antebrazo menos largo } \\
\text { y ligeramente oblicuo. } \\
\text { Codo redondeado. Asas } \\
\text { bífidas o semibífidas, de } \\
\text { longitud mediana y con } \\
\text { proyección vertical }\end{array}$ & $\begin{array}{l}\text { Antebrazo horizontal y } \\
\text { corto. Codo en ángulo } \\
\text { recto. Asas semibífidas, } \\
\text { anchas, abastonadas y de } \\
\text { longitud mediana }\end{array}$ & $\begin{array}{l}\text { Antebrazo horizontal y } \\
\text { corto. Codo en ángulo } \\
\text { recto. Asas anchas, } \\
\text { semibífidas, muy largas } \\
\text { y abastonadas }\end{array}$ \\
\hline Carena & Suave y semiredondeada & $\begin{array}{l}\text { Más pronunciada y } \\
\text { semiredondeada }\end{array}$ & $\begin{array}{c}\text { Marcada en ángulo } \\
\text { obtuso }\end{array}$ & $\begin{array}{l}\text { Muy marcada en ángulo } \\
\text { recto }\end{array}$ \\
\hline Cuerpo & $\begin{array}{c}\text { Ovalado, de menor } \\
\text { altura y mayor diámetro }\end{array}$ & $\begin{array}{c}\text { Ligeramente ovalado al } \\
\text { ser más alargado } \\
\end{array}$ & Más alto y cilíndrico & $\begin{array}{l}\text { Alto, claramente } \\
\text { cilíndrico }\end{array}$ \\
\hline Pivote & Corto y macizo & Algo más alto y macizo & Largo y macizo & $\begin{array}{l}\text { Muy largo, macizo, } \\
\text { pesado, prominente, con } \\
\text { la punta moldurada }\end{array}$ \\
\hline
\end{tabular}

Figura 9. Tabla resumen con el primer borrador sobre los rasgos distintivos generales de las cuatro variantes layetanas. 
sus rasgos primitivos detalles amorfos comunes a la Pascual 1, al formar parte, por un tiempo limitado, de la misma cadena productiva en las figlinae. La forma 3 "clásica" o convencional (B) la datamos en el primer cuarto del siglo I d.C. Sugerimos, con cautela, situar el punto de separación entre las formas Dressel 3 y 2 hacia el año 30 d.C., obviamente, pensando en la existencia de ánforas con rasgos intermedios de transición. La forma 2 "clásica" o convencional (C) la datamos desde los últimos años del reinado de Tiberio hasta mediados del siglo I d.C. El tramo de vida restante es para la forma 2 tardía (D), la de aspecto más robusta y evolucionada.

\section{CONCLUSIONES}

La razón de ser del término Dressel 2-4 tarraconense es un "sinsentido científico" lleno de contradicciones, heredado desde la publicación de Dressel sobre las ánforas de Castro Pretorio y aceptado por la investigación como dogma. Sus límites son imprecisos por la naturaleza del trabajo de Dressel, quien no tuvo la intención de hacer una clasificación de las ánforas romanas por criterios crono-tipológicos. Las formas 2, 3 y 4 son, a nuestro entender, duplicaciones de la misma clase de objeto con una serie de matices que derivan de circunstancias temporales y geográficas en la fabricación de estos envases. Las formas 3 y 4 tienen un aspecto afín, fueron coetáneas y precedieron a la forma 2. Su desigualdad en el diseño parece deberse a un posible factor regional arraigado entre las producciones itálicas.

Las provincias de la vertiente occidental del Mediterráneo comenzaron a producir estas ánforas hacia finales del siglo i a.C., escogiendo como modelo económico la forma 3 del prestigioso vino de Campania. Este detalle es importante, porque nos aclara el motivo por el que no tenemos ejemplares de la otra forma 4 itálica en la Tarraconense.

La forma 4 debe ser suprimida de la lista tarraconense para ceñirnos únicamente al grupo Dressel 2-3. Estas dos formas no fueron coetáneas en el tiempo, tal y como se había pensado hasta ahora como envases alternativos para comercializar los mismos vinos de una región. En realidad, la Dressel 2, que datamos desde los últimos años del reinado de Tiberio, es el resultado de la evolución de la forma 3, como recipiente optimizado para el transporte naval de larga distancia, seguramente, con un toque morfológico regional mucho más acentuado.

El orden de la numeración Dressel 2-3 carece pues de sentido cronológico ascendente, al ser la forma 3 anterior a la 2. Sería más acertado llamarla Dressel
3-2 aunque resultase extraña la terminología con los números colocados al revés de mayor a menor. Pero aun así, este término se contradice a sí mismo como definición de clase, porque los dos números apuntan a un mismo objeto con valores cronológicos diferentes. Para ser coherentes con una clasificación taxonómica bastará con asignar un único número a esta clase de ánfora, ayudados luego por letras para distinguir las variantes evolutivas, como ya hiciera Nino Lamboglia al estudiar las ánforas Dressel 1 y subdividirlas en tres grupos (A, B, C).

En definitiva, se busca un nuevo nombre para referirnos a estos envases de manera segura, con un término científico ajustado a su significado. El tipo Dressel 2-4 debe ser descartado de las clasificaciones anfóricas por las múltiples contradicciones aquí expuestas. Su uso irreflexivo nos ha ofuscado durante todos estos años. No hemos sido capaces de percibir que existía un factor evolutivo tras los rasgos morfológicos cambiantes de estos envases. Desde ahora es posible extraer dataciones relativas más precisas a estos materiales examinando sus rasgos generales.

Este trabajo pone en manos del investigador un modelo teórico de clasificación crono-tipológico que permite datar con mayor precisión estas ánforas y su epigrafía asociada. Cabe desde este momento mejorar sus bases descriptivas, afinar las cronologías, sobre todo, analizando el material en los lugares de producción con una visión de conjunto.

\section{BIBLIOGRAFÍA}

Almagro, M. 1951: "El recinto sepulcral romano tardío de El Castellet de Ampurias", Archivo Español de Arqueología 24, 99-116.

Almeida, R. de, Van der Berg, J., Berni, P., Schimmer, F. y Carreras, C. 2014: "El comercio de ánforas hispanas en Kops Plateau (Nijmegen) desde época de Augusto a época flavia”, R. Morais, A. Fernández y M. J. Sousa (eds.), As produções cerâmicas de imitaçao na Hispania, Monografías Ex Officina Hispana II, Porto, 379-392.

Aranegui, C. 1981: "La producción de ánforas romanas en el País Valenciano: estado de la cuestión", Archivo de Prehistoria Levantina XVI, Valencia, 529-538.

Beltrán Lloris, M. 1970: Las ánforas romanas en España, Anejos de Caesaraugusta VIII, Zaragoza.

Benoît, F. 1957: "Typologie et apigraphie amphoriques, les marques de Sestius", Rivista Studi Liguri 3-4, 247-285.

Bernal, D., Sáez Romero, A.M., Montero Fernández, R., Díaz Rodríguez, J.J., Sáez Espligares, A., 
Moreno, D. y Toboso Suárez, E.J. 2005: “Insatalaciones fluvio-marítimas de drenaje con ánforas romanas. A propósito del embarcadero flavio del Caño de Sancti Petri (San Fernando, Cádiz)", Spal 14, 179-230.

Bernard, H. 2007: "Nouvelles èpaves hispaniques de Corse: Sud Perduto 2 (Bonifacio) et Marina di Fiori (Porto Vecchio)", Comercio, redistribución y fondeadores: la navegación a vela en el Mediterráneo, V Jornadas de Arqueología Subacuática, Valencia, 461-471.

Berni Millet, P. 1998: Las ánforas de aceite de la Bética y su presencia en la Cataluña romana, Col·lecció Instrumenta 4, Barcelona.

Berni Millet, P. 2010: "Epigrafia sobre amphorae, tegulae, imbrex i dolia a l'àrea occidental del Camp de Tarragona", D. Gorostidi Pi , Ager Tarraconensis 3. Les inscripcions romanes, Sèrie Documenta 16, Tarragona, 153-210.

Berni Millet, P. 2015: "Novedades de epigrafía anfórica en el Baix Llobregat", V. Martínez Ferreras (ed.), La difusión comercial de las ánforas vinarias de Hispania Citerior Tarraconensis ( $s$. I a.C. - I. d.C.), Archaeopress Roman Archaeology, 4, 55-66.

Berni Millet, P. y Carreras Monfort, P. 2013: "Corpus epigràfic de segells en àmfora, dolia, tegulae i gerres de ceràmica comuna oxidada del Baix Llobregat", Barcino II: Marques i terrisseries del Baix Llobregat, Barcelona.

Berni Millet, P. y Miró, J. 2013: "Dinámica socioeconómica en la Tarraconense oriental a finales de la República y comienzos del Imperio. El comercio del vino a través de la epigrafía anfórica”, J. López (ed.), Tarraco Biennal. Actes del ler Congrès Internacional d'Arqueologia i Món Antic. Govern i societat a la Hipània Romana, Novetats epigràfiques. Homenatge a Géza Alföldy, Tarragona, 63-83.

Callender, M. H. 1965: Roman Amphorae, with index of Stamps, Oxford University Press.

Comas i Solà, M. 1985. Baetulo. Les àmfores, Monografies Badalonines 8, Badalona.

Delattre, A.L. 1906: "Un second mur à amphores découvert à Carthage", Bulletin de la société archéologique de Sousse 1er semestre, 33-48.

Dell'Amico, P. y Pallarés, F. 2005: "Il relitto di Diano Marina e le navi a 'dolia': nuove considerazioni”, T. Cortis y T. Gambin (eds.), De Triremibus, Festschrift in honour of Joseph Muscat, Malta, 67-114.

Dell'Amico, P. y Pallarés, F. 2007: "Le anfore della Laietania. Appunti e riflessioni”, Archeologia Marittima Mediterranea. An International Journal on Underwater Archaeology 4, 53-133.
Dressel, H. 1879: "Di un grande deposito di anfore rivenuto nel nuovo quartiere del Castro Pretorio", Bullettino della Commissione Archeologica Comunale di Roma, Anno VII - Serie seconda, 36-64, Tav. VII-XVIII.

Farinas del Cerro, L., Hesnard, A. y Fernandez de la Vega, W. 1977: "Contribution à l'établissement d'une typologie des amphores dites Dressel 2-4", Méthodes classiques et méthodes formelles dans l'étude typologique des amphores, Actes du colloque de Rome, Roma, 179-206.

Freed, J. 1998: "Stamped Tarraconensian Dressel 2-4 Amphoras at Carthage", II Col.loqui Internacional d'Arqueologia Roman. Actes, El vi a l'antiguitat: Economia, produccio i comerc al Mediterrani occidental, Monografies Badalonines 14, 350-356.

García Vargas, E., Almeida, R. y González Cesteros, H. 2011: "Los tipos anfóricos del Guadalquivir en el marco de los envases hispanos del siglo I a.C. Un universo heterogéneo entre la imitación y la estandarización", Spal 20, 185-283.

Gianfrotta, P.A. y Hesnard, A. 1987: "Due relitti augustei carichi di dolia. Quelli di Ladispoli e del Grand Ribaud D", El vi a l'Antiguitat. Economia producció i comerç al Mediterrani Occidenta, I Col-loqui d'Arqueologia Romana, Badalona, 285-297.

Gisbert, J.A. 1987: "La producció del vi al territori de Dianum durant l'Alt Imperi: el taller d'àmfores de la vil-la romana de l'Almadrava (Setlamirarrosa - Miraflor)", El vi a l'Antiguitat. Economia, producció i comerç al Mediterrani occidental, I Col-loqui d'Arqueologia Romana, Badalona, 104-118.

González Cesteros, H. y Tremmel, B. 2013: "Aceite, vino y salazones hispanos en Oberaden", De vino et oleo Hispaniae. Áreas de producción y procesos tecnológicos del vino y el aceite en la Hispania romana, Anales de Prehistoria y Arqueología de la Universidad de Murcia 27-28, Murcia, 527-542.

González Cesteros, H. 2014: Ánforas hispanas en la Germania Inferior antes de la formación de la provincia (20 a.C.-69 d.C.), Tesis Doctoral inédita, Tarragona.

Grace, V.R. 1961: Amphoras and the ancient wine trade, Excavations of the Athenian Agora 6, Princeton.

Grenier, A. 1934: Manuel d'archéologie préhistorique, celtique et gallo-romaine, J. Déchelette VI (2), Paris.

Hesnard, A., Carre, M-B, Rival, M., Dangréaux, B., Thinon, M., Blaustein Dumontier M., Chéné A., Foliot, P. y Bernard-Maugiron, H. 1988: "L'épave romaine Grand Ribaud D (Hyères, Var)", Archaeonautica $8,5-180$. 
Járrega, R. 2008: "La producció vinícola i els tallers d'àmfores a l'ager Tarraconensis i l'ager Dertosanus", M. Prevosti y A. Martín (eds.), El vi tarraconense i laietà: ahir $i$ avui, Actes del simpòsium, Sèrie Documenta 7, 99-123.

Lamboglia, N. 1955: "Sulla cronologia delle anfore romane di etá republicana (II-I secolo a.C.)", $R i$ vista Studi Liguri 21 (3-4), 241-270.

Laubenheimer, F. 1989: "Les amphores gauloises sous l'Empire. Recherches nouvelles sur leur production et leur chronologie", Amphores romaines et histoire économique. Dix ans de recherche. Actes du colloque de Sienne, École Française de Rome, Roma, 105-138.

Liou, B. y Domergue, C. 1990: "Le commerce de la Bétique au Ier siècle de notre ère. Notes sur l'épave Lavezzi 1 (Bonifacio, Corse du Sud)", Archaeonautica 10, 125-155.

Loeschke, S. 1909: "Keramische Funde in Haltern. Ein Beitrag zur Geschichte der Augusteischen Kultur in Deutschland", Mitteilungen der Altertumkommission für Westfallen II, Münster, 101-257.

Loeschke, S. 1942: "Die römische und belgische Keramik aus Oberaden", C. Albrecht (ed.), Das Römerlager in Oberaden und das Uferkastell in Beckinghausen an der Lippe, Dortmund, 7-148.

López Mullor, A. y Martín Menéndez, A. 2008: “Tipologia i datació de les àmfores tarraconenses produïdes a Catalunya", La producció $i$ el comerç de les àmfores de la provincia Hispania Tarraconensis, Homenatge a Ricard Pascual i Guasch, Barcelona, 33-94.

Martínez Ferreras, V. 2014: Ánforas vinarias de Hispania Citerior-Tarraconensis (s. I a.C.- I d.C.), Roman and Late Antique Mediterranean Pottery 4, Oxford.

Marty, F. y Zaaraoui, Y. 2009: “Contextes céramiques du haut-empire de la bonification de l'Estagnon à Fos-sur-mer (Bouches-du-Rhône)", SFECAG, Actes du Congrés de Colmar, Marseille, 397-426.

Miró Canals J. 1988: La Producción de ánforas romanas en Catalunya, BAR Int. Series 473, Oxford.

Nolla J.M. y Solías, J.M. 1984: "L'àmfora tarraconense 1. Característiques, procedència, àrees de producció, cronología”, Butlletí Arqueològic de Tarragona 6-7, 107-144.

Oxé, A., Comfort, H. y Kenrick, P. 2000: Corpus Vasorum Arretinorum. A Catalogue of the Signatures, Shapes and Chronology of Italian Sigillata ( $2^{\mathrm{a}}$ ed.), Bonn.

Pallarés, F. 1983: La nave romana del golfo di Diano Marina. Relazione preliminare della campagna 1981, Forma Maris Antiqui XI-XII (1975-1981), Bordighera.
Pallarés, F. 1985: "La nave romana di Diano Marina, Relazione preliminare", VI Congreso internacional de Arqueología submarina, Madrid, 285-296.

Panella, C. 1970: “Anfore”, Ostia II, Roma, 102-264.

Panella, C. y Fano, M. 1977: "Le anfore con anse bifide conservate a Pompei: contributo ad una loro classificazione", Méthodes classiques et méthodes formelles dans l'étude typologique des amphores, Actes du colloque de Rome, Roma, 133-177.

Pascual Guasch, R. 1962: "Centros de producción y difusión geográfica de un tipo de ánfora", VII Congreso Nacional de Arqueología, Zaragoza, 334-345.

Pascual Guasch, R. 1977: "Las ánforas de la Layetania", en: Méthodes classiques et Méthodes Formelles dans l'Étude des Amphores, Actes du Colloque de Rome, Roma, 47-96.

Pelichet, E. 1946: "A propos des amphores trouvées a Nyon", Zeitschrift für schweizerische Archäologie und Kunstgeschichte 8, 189-202.

Piccottini, G. 1997: "Amphorae litteratae vom Magdalensberg", Erath, G. et alii (eds.), Komos, Festschrift für Thuri Lorenz zum 65. Geburtstag, Wien, 203-206.

Sciallano, M. y Liou, B. 1985: "Les épaves de Tarraconaise à chargement d'amphores Dressel 2-4", Archaeonautica 5.

Sciallano, M. y Marliere, S. 2008: "L'èpave à dolia de l'île de la Giraglia (Haute-Corse)", Archaeonautica 15, 113-151.

Tchernia, A. 1964: "Amphores et marques d' amphores de Bétique à Pompéi et à Stabies", Mélanges d'archéologie et d'histoire de l'École Française de Rome 76 (2), 419-449.

Tchernia, A. 1971: "Les amphores vinaires de Tarraconaise et leur exportation au début de l'Empire", Archivo Español de Arqueología 44, 38-85.

Tchernia, A. y Zevi, F. 1972: "Amphores vinaires de Campanie et de Tarraconaise à Ostie", Recherches sur les amphores romaines, Actes du Colloque de Rome, Publications de l'École française de Rome 10, Roma, 35-67.

Tchernia, A. 1986: Le vin de l'Italie romaine. Essai d'histoire économique d'après les amphores, Roma.

Vegas, M. 1973: Cerámica común romana del Mediterráneo Occidental, Barcelona.

Zevi, F. 1966: "Appunti sulle anfore romane", Archeologia Classica XVIII, 208-247.

Recibido: 03-01-2015

Aceptado: 12-05-2015 